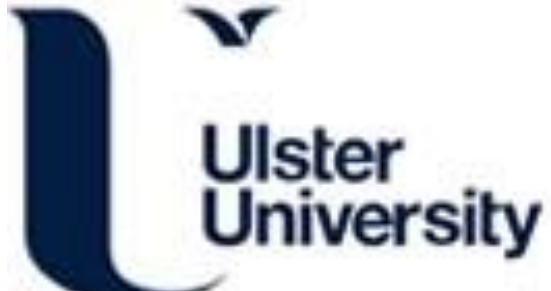

Structural response of unprotected and protected slim floors in fire

Alam, N., Nadjai, A., Ali, F., \& Nadjai, W. (2018). Structural response of unprotected and protected slim floors in fire. Journal of Constructional Steel Research, 142, 44-54. https://doi.org/10.1016/j.jcsr.2017.12.009

Link to publication record in Ulster University Research Portal

Published in:

Journal of Constructional Steel Research

Publication Status:

Published (in print/issue): 31/03/2018

DOI:

10.1016/j.jcsr.2017.12.009

Document Version

Author Accepted version

\section{General rights}

Copyright for the publications made accessible via Ulster University's Research Portal is retained by the author(s) and / or other copyright owners and it is a condition of accessing these publications that users recognise and abide by the legal requirements associated with these rights.

\section{Take down policy}

The Research Portal is Ulster University's institutional repository that provides access to Ulster's research outputs. Every effort has been made to ensure that content in the Research Portal does not infringe any person's rights, or applicable UK laws. If you discover content in the Research Portal that you believe breaches copyright or violates any law, please contact pure-support@ulster.ac.uk. 


\title{
Structural Response of Unprotected and Protected Slim Floors in Fire
}

\author{
Naveed Alam ${ }^{1}$, Ali Nadjai ${ }^{2}$, Faris Ali ${ }^{3}$, Walid Nadjai ${ }^{4}$
}

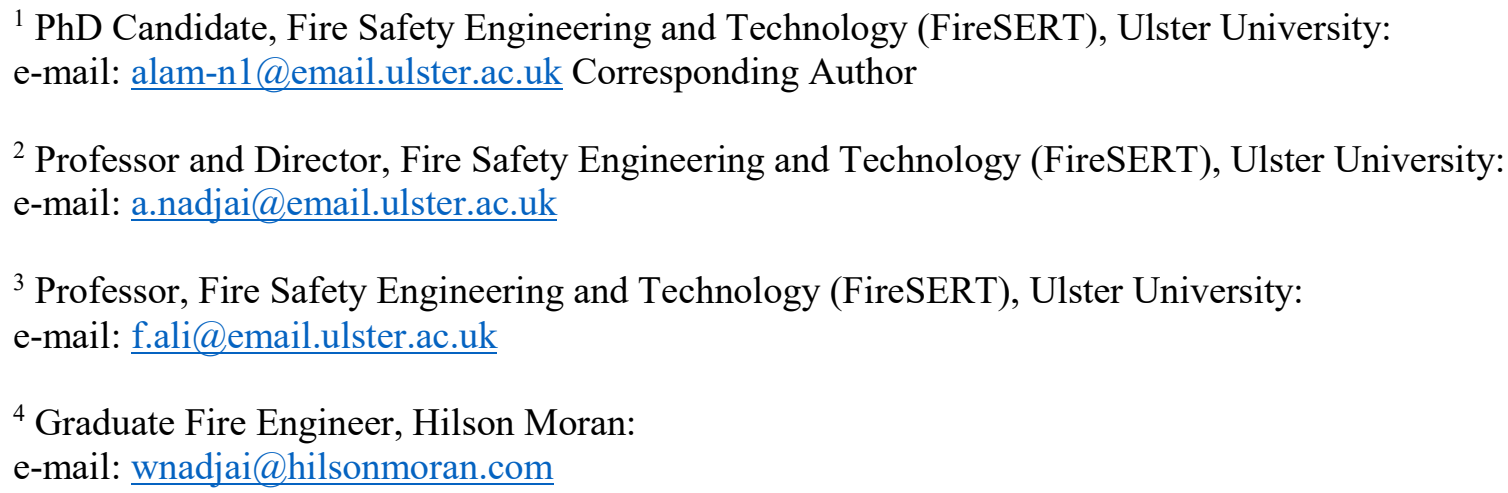

\section{ABSTRACT}

Slim floor systems are a latest addition to the existing construction types and are currently being used for various construction purposes. Preference of slim floors over traditional composite floors is due to their ease of construction, when combined with steel decking. Considerable amount experimental work on fire response of slim floors has been conducted since 1980s. Though, these floors offer a better fire resistance, however, fire protection materials including intumescent coatings are often used in situations where a higher fire resistance is desired. Fire tests have also been conducted to analyse the performance of intumescent coating applied on steel elements as a protection material. This study presents a finite element analysis approach to model the behaviour of unprotected and protected slim floors in fire. Initially, FE analysis has been performed to model the thermo-mechanical behaviour of unprotected slim floors and results obtained have been verified against the reported test data. In the middle part, thermal behaviour of an intumescent coating, applied on a steel element as a fire protection, has been modelled and verified. The verified models have finally been combined to perform thermo-mechanical analysis for slim floors protected with intumescent coating. Results show that the protected slim floors offer a higher fire resistance as the temperature of the steel section remains within $400^{\circ} \mathrm{C}$ even after 60 minute standard fire exposure. Lower temperatures in steel result in lesser reductions of strength and stiffness, hence, the protected slim floors undergo lesser deflections and offer higher fire resistance.

\section{Keywords:}

Slim floors, Finite Element modelling, Intumescent coating, Fire Resistance

\section{INTRODUCTION}

Slim floors are amongst the trending methods of construction for high rise residential and commercial buildings and for car parks (1). Popularity of these floorings is attributed to their shallower depths in 
comparison to that of traditional steel-concrete composite floors with down-stand steel beams. These floors not only result in a reduction of floor depth itself, but, also reduce the overall height of structure. These floorings offer numerous advantages including, reduction in usage of construction material due to lesser structure height, ease of construction when combined with steel decking, lesser cost requirements, possibility to accommodate services within floor depth through web openings and reduced carbon emissions resulting during manufacturing process due to lesser material consumption (2). Steel beam section in these floors is encased within the floor depth, hence, these floors are believed to offer a higher fire resistance as steel section is saved from direct exposure to fire (3). Numerous tests have been conducted on slim floors to study and analyse their response in fire. These include tests conducted on their thermal and thermo-mechanical response against different fire conditions. Many of the tests have been conducted at the Warrington Fire Research Centre (WFRC) in collaboration with British Steel.

This study focuses on the response of protected and unprotected slim floors in fire. In the initial part, Finite Element (FE) modelling has been performed for two slim floor assemblies exposed to ISO-834 standard fire. The modelled test assemblies are same as the ones used during fire tests conducted in the literature (4) (5). Predictions from the FE analysis are then verified against the reported test data. In the second part of this study, thermal response of an intumescent coating applied on a steel element as a fire protection material has been modelled and verified against the test data (6). Finally, the verified models have been combined to simulate the response of assumed protected slim floor assemblies exposed to standard fire. The assumed protected slim floors are similar to the unprotected floors used during tests with only exception that a layer of intumescent coating has been added on the exposed surfaces of the bottom flange. FE modelling for protected floors has been performed with degree of utilization similar to that adopted during the fire tests on the unprotected assemblies. Response of the protected slim floors under full degree of utilization has also been predicted to check their behaviour in such a scenario. In an earlier study, behaviour of such floors in fire is analysed using two different modelling tools (7). The earlier study is limited to their thermal response only, while in this study, FE modelling to predict thermal and thermo-mechanical response of unprotected and protected slim floors is performed in detail (4) (5).

\section{EXPERIMENTAL WORK}

Experimental work used during this study is adopted from tests conducted and reported before as no experimental work was conducted during this study by the authors. Details of the tests conducted on slim floor assemblies and on the intumescent coating are given in the following.

\subsection{Tests on Slim Floors}

WFRC in collaboration with the British Steel conducted various tests to study thermal and thermomechanical response of slim floors in fire. During these tests, rolled asymmetric slim floor beam (ASB) 
sections were used in combination with composite slab formed using steel decking and normal weight concrete. Two such tests, WFRC 66162 and WFRC 67756, conducted to analyse their thermomechanical response are used in this study. Both fire tests were conducted against standard fire exposure, the standard temperature time curve, ISO-834 (8).

Test WFRC 66162 , was conducted on the $14^{\text {th }}$ of February 1996 on a $5000 \mathrm{~mm}$ long slim floor assembly spanning $4500 \mathrm{~mm}$ between supports. This test assembly consisted of an ASB 280 rolled steel beam section and a composite slab. The composite slab was formed using Comflor 210 steel decking and normal weight concrete. Nominal depth of the assembly was $308 \mathrm{~mm}$ while the width was $950 \mathrm{~mm}$ as shown in Figure 1. Depth of the steel beam section was $280 \mathrm{~mm}$ while the width of top and bottom flange was $180 \mathrm{~mm}$ and $280 \mathrm{~mm}$ respectively. Thickness of flanges and web were uniform and was 18 $\mathrm{mm}$ as shown in Figure 1. A $28 \mathrm{~mm}$ concrete layer reinforced with A-142 steel mesh was laid above the top flange. Dimensions of the steel beam section were found to be slightly different and are given in comparison to nominal ones in Table 1. Aside from the geometric variations, actual yield strength of the structural steel was found to be $402 \mathrm{MPa}$, much higher than the nominal value of $355 \mathrm{MPa}$. Further details can be found in a technical note published by the British Steel (4).

During the test, detailed instrumentation was conducted to record temperatures and vertical deflections. 153 K-type thermocouples were used to record temperatures on steel part at various locations along its length. In addition, temperatures were also recorded at 30 different locations in concrete and at 3 locations on the steel decking. Vertical deflections of the floor were recorded at six distinct locations along its length including that at mid-span. External load was applied at four locations, directly to the steel beam section through hydraulic rams. Each hydraulic ram applied $84.6 \mathrm{kN}$ load which in addition to the self-weight induced a $198.81 \mathrm{kN}-\mathrm{m}$ moment in the test assembly. This applied moment represented a 0.423 degree of utilization when compared to the cold capacity of the test assembly. Hydraulic rams were located $1125 \mathrm{~mm}$ apart. Under this degree of utilization, the test specimen was expected to achieve a fire resistance of more than 60 minutes based on the results of analysis ignoring the enhanced action between steel and concrete (4). The slim floor assembly was tested against ISO834 standard fire (8).

The second test, WFRC 67756, was conducted on the $4^{\text {th }}$ of September 1996. Details and observations made before, during and after the test are published as a report (5). These include details on geometry, material properties and thermal and structural data recorded. This test was conducted on a slim floor assembly consisting of an ASB section. Nominal depth of the floor assembly was $334 \mathrm{~mm}$ while the width was $1000 \mathrm{~mm}$ as shown in Figure 2. Steel with a $355 \mathrm{MPa}$ yield strength was used to form the steel beam section which was $304 \mathrm{~mm}$ deep. Nominal widths of the top and bottom flanges were 190 $\mathrm{mm}$ and $300 \mathrm{~mm}$ respectively. The nominal thickness of flanges was $20 \mathrm{~mm}$ while that of the web was $18 \mathrm{~mm}$. A $30 \mathrm{~mm}$ layer of normal weight concrete was laid above the top flange and was reinforced 
with A-142 steel mesh. Measured dimension of the of the steel section differed to nominal ones as given

109 in Table 2. Apart from the geometric variations, the actual yield strength of the structural steel was 110 found to be $392 \mathrm{MPa}$, higher than the nominal $355 \mathrm{MPa}$ strength (5).

111 Similar to the previous test, instrumentation to record temperatures and displacements was done during

112 the test. K-type thermocouples were used to record temperatures in the steel beam across its section at 113 various locations along its length. In addition, temperatures were recorded in concrete and on steel 114 decking. Vertical deflections of the floor assembly were recorded at mid-span. Load was applied at four 115 locations though hydraulic rams $530 \mathrm{~mm}$ apart. Each hydraulic ram applied $85 \mathrm{kN}$ load which in 116 addition to the self-weight induced a moment representing 0.390 of its capacity at ambient temperatures.

117 Calculated moment resistance of the specimen was $796 \mathrm{kNm}$ at normal conditions. Capacity of the 118 assembly is based on the results from analysis ignoring the enhanced action between steel and concrete 119 only considering the resistance offered by the steel section alone. Like in the case of the previous test, 120 slim floor assembly was tested against standard fire exposure, ISO-834.

\section{$121 \quad 2.2 \quad$ Test on Intumescent Coating}

122 Various experimental investigations were performed to analyse the response of intumescent coating as 123 a fire protection material. These tests were conducted on protected steel elements with intumescent 124 coating. The protected surfaces of these specimen are exposed to standard fire, ISO-834, in a furnace 125 and response of intumescent coating is analysed. The selected test was conducted on a steel angle with 126 intumescent coating applied on external surface of one leg (6). The steel angle has square shaped legs 127 with outer dimensions of $100 \mathrm{~mm}$ each. These legs have uniform thickness of $10 \mathrm{~mm}$. On the outer 128 surface of one leg, a $1200 \mu \mathrm{m}$ layer of intumescent coating was applied. The specimen is then exposed 129 to fire in a furnace with protected surface exposed directly to fire (6). Other surfaces and edges of the 130 specimen were protected using mineral wool and plaster board to create adiabatic boundary conditions 131 as shown in Figure 3.

132 Response of intumescent in fire conditions is dependent on various parameters including the section 133 factor of the elements on which it is applied. The specimen used for the intumescent coating test 134 described above has a section factor of $53 \mathrm{~m}^{-1}$. This section factor is close to the section factors of the 135 slim floors WFRC 66162 and WFRC 67756, which are $61.5 \mathrm{~m}^{-1}$ and $55.08 \mathrm{~m}^{-1}$ respectively, when the 136 outer surfaces of the bottom flange are protected and section factor is calculated using eqn [1] (9). 137 Hence, the behaviour of intumescent coating when applied on these slim floor assemblies is expected 138 to be similar to that in case of the test performed on the steel angle with similar section factor.

$$
\frac{A_{E X P}}{V_{T O T}}=\frac{P_{E X P}}{A_{T O T}}=\frac{P_{E X P \_B O T T O M_{\_} F L A N G E}}{A_{T O T \_B O T T O M} F L A N G E}
$$




\section{FINITE ELEMENT MODELLING}

141 Details of the FE modelling method used during this study are presented in the proceeding sections. In the first part, FE modelling used for unprotected slim floors is discussed while in the second part, the same for the test on intumescent coating is given in detail. Finally, FE modelling procedure for assumed protected slim floor assemblies is provided.

\subsection{Unprotected slim floors}

FE modelling for slim floors is performed using ABAQUS (10), a commercial software used to perform finite element analyses and for computer aided engineering. FE modelling consists of two phases. The first phase where thermal analysis is performed while in the second phase structural analysis is performed. All external loadings, fire exposure and boundary conditions are in accordance with the reported test data (4) (5). During thermal analysis, non-linear thermal properties of steel and concrete (thermal conductivity and specific heat) are taken from the Eurocodes (11). The mechanical properties of materials during structural analysis have also been taken from the Eurocodes (11) with the exception that the actual yield strength for structural steel is used instead of the nominal values. Full scale FE models are developed for both slim floors during this study.

8 node hexahedral solid linear heat transfer elements, DC3D8, are used during thermal analysis phase. Convection coefficient for exposed and unexposed surfaces are $25 \mathrm{~W} / \mathrm{m}^{2} \mathrm{~K}$ and $9 \mathrm{~W} / \mathrm{m}^{2} \mathrm{~K}$ respectively as given in the Eurocodes (12). Radiation emissivity for the exposed steel surfaces is taken 0.5 from a previous study (14) (15) while the same for exposed concrete surfaces was taken as 0.25 from Eurocodes (13). Any heat losses due to radiation from the unexposed surfaces are ignored during the analysis. Thermal predictions obtained during the first phase are applied to the slim floor to study the effects of heating on its structural response in later part of the analysis. In second phase, structural analysis is performed in two steps. In the first step, loads are applied to the assembly while in the later step, the slim floor assembly is heated using the temperature predictions obtained from first phase. Unlike the case in tests where 4-point loading was used, a uniformly distributed load is applied during FE modelling as a representative of the test load. For structural analysis, distinct set of analysis elements are employed for concrete and steel. Concrete is modelled using 8-node linear brick elements, C3D8, while the steel is modelled using incompatible mode elements, C3D8I. These elements were found to yield better results in comparison to other available element types in ABAQUS (14) (15). Non-linear behaviour of concrete is modelled using 'the concrete damaged plasticity model' while the same for steel is modelled using 'Von Mises plastic model'. Dilation angle has been set to $55^{\circ}$ for the same reasons mentioned previously (14) (15). Contact between concrete and steel is modelled using the contact pair option available in the software. Perfect thermal contact is modelled between the two materials with no heat losses. In case of structural modelling, tangential behaviour for concrete and steel is modelled using 'Coulomb friction model' by defining a coefficient of friction. The value of this 


\subsection{The intumescent coating}

178 A full-scale FE model is developed for the test on intumescent coating described before which was conducted on steel angle with a $1200 \mu \mathrm{m}$ layer of intumescent coating applied on the exposed surface.

180 Similar to the slim floor case, 8 node hexahedral solid linear heat transfer elements, DC3D8, are used

181 to model its thermal response. Thermal properties of the structural steel, thermal conductivity and specific heat, are taken from the Eurocodes as in the case of the slim floors (13). In case of the applied intumescent coating, the thermal conductivity (shown in Figure 4) was found to vary at different temperatures during the test, hence was modelled accordingly. Other properties of intumescent coating, specific heat, density, water content, convection coefficient and radiation emissivity are taken from an earlier reported work (17). For the exposed surfaces, convection coefficient and radiation emissivity are taken 20 and 0.95 respectively as given in Table 3. FE analysis of intumescent coating on steel angle was performed to assess the validity of FE modelling approach used in this study so that the verified method can be used to model the response of intumescent coating applied on assumed protected slim floors in the later part. As fire protection materials are assumed to have no contribution to the structural capacity of the members, hence, the test and the FE modelling for intumescent coating are limited to thermal response only and no investigations on structural response have been conducted.

\subsection{Protected slim floors}

194 Though no tests on protected slim floors were used during this study for a direct comparison of test results and predicted response, however, FE analysis is performed for assumed protected slim floors by combining the verified models for unprotected slim floor tests and for intumescent coating test described before. Simulated protected slim floors are similar to the unprotected slim floors described previously except that a layer of intumescent coating, $1200 \mu \mathrm{m}$, is assumed to be applied on exposed surfaces of the bottom flange of the steel section as shown in Figure 5. Thermal and mechanical properties of all materials, steel, concrete and intumescent coating, are same as those discussed in previous sections. Response of protected slim floor in fire is analysed in two phases, thermal and structural. In first phase, thermal analysis is performed for protected slim floors and temperature predictions are obtained. While in the later phase, the combined effect of loading and heating is analysed in two steps. Initially, loads are applied which is followed by heating the assembly with thermal predictions obtained during the first phase. The FE modelling is performed to analyse the behaviour of protected slim floors under the same loads as used during the tests conducted on unprotected slim floors. 
where no load reductions take place in a fire scenario. It should be noted that any structural contribution

210 of the intumescent coating applied is ignored during this study.

\section{OBSERVATIONS AND FINDINGS}

212 Predictions on the thermal and structural response obtained from the FE modelling are presented in this

213 section. These predictions are given in comparison with the recorded test data for unprotected slim

214 floors and for test on intumescent coating while for protected slim floors, these are presented in

215 comparison to thermal and structural predictions obtained during the FE analysis performed for

216 unprotected slim floors.

\section{$217 \quad 4.1 \quad$ Unprotected slim floors}

218 Both tests conducted on the slim floors were well instrumented to measure temperature development

219 and vertical deformations at various locations along their length. During the test, thermal and deflection

220 recordings were made on the steel and in concrete and are reported in form of spread sheets (18).

221 Thermal predictions obtained during the FE modelling are given in comparison to the test data obtained

222 for different locations on steel part and in concrete. For this purpose, two distinct locations are selected

223 on the test assembly due to geometric variations. These locations are referred to as section A-A and

224 section B-B in this paper. Section A-A represents the part of the slim floor with maximum concrete

225 depth and width resulting from the shape of decking. On the other hand, section B-B represents the part

226 of slim floor with minimum concrete depth and lowest concrete width on both sides of steel web as

227 shown in Figure 1 and Figure 2. Although test data is available for various such locations, comparisons

228 are only for two selected locations to avoid unnecessary repetitions. The selected locations being in the

229 middle of the furnace are expected to be least influenced by the boundaries, the furnace walls, etc.

230 Numerical results on structural response are verified by comparing the predictions with recorded test 231 data on vertical deflection at mid-span in each case.

232 Temperature predictions for WFRC 66162 after an exposure of 120 minutes are given in Figure 6 (a).

233 It is seen that the maximum temperatures on the exposed surfaces have exceeded $1000^{\circ} \mathrm{C}$. As expected,

234 these predictions are highest on the exposed surfaces towards the bottom flange and reduce with

235 increasing distance towards the unexposed upper surface. For a direct comparison with the test data,

236 temperature predictions at five thermocouple locations on steel part (Figure 1 (a) and (b)) are plotted

237 against the test data in Figure 7. The selected five locations represent two thermocouple locations on

238 the bottom flange, two on web and one on the top flange. It is seen in Figure 7 (a) that temperature

239 predictions are in very good agreement with the recorded test data for section A-A. Similarly,

240 temperature predictions obtained for section B-B are plotted against test data for the same thermocouple

241 locations. These predictions are also in very good agreement with the recorded test data (Figure 7 (b)).

242 Hence this FE modelling approach provides good temperature predictions for distinct locations on steel

243 section irrespective of the geometric variations along the span. 
244 In addition to the steel part, temperature predictions obtained for three distinct thermocouple locations 245 in the concrete slab (Figure 1 (b) and (c)) are also plotted against the recorded test. The selected 246 locations represent concrete part at section A-A and section B-B. These temperature predictions are also 247 in good agreement with the reported test data as shown in Figure 8. Hence, the FE modelling approach 248 used is suitable to obtain thermal predictions for slim floors irrespective of the material type.

249 Structural response of slim floor assembly is evaluated based on predicted vertical deformations 250 obtained from the analytical investigation. Figure 9 shows the deformed shape of WFRC 66162 test assembly at the end of FE analysis. Deflection is maximum at the mid span and decreases with increase in distance towards the supports from centre. The slim floor assembly displayed a fire resistance of 102 minutes at which the predicted deflection was $186.5 \mathrm{~mm}$. At this point, materials lost their strength and stiffness as a result the slim floor assembly was not able to sustain any further loading, hence, failure occurred. Predicted mid-span deflection is plotted against recorded test data in Figure 10. The predicted deflection is in very good agreement with test data. Further the deflection trend over heating period is also similar. Hence, FE modelling approach used in this study is not only capable of providing thermal predictions but also provides thermo-mechanical predictions for slim floors with accuracy.

Efficiency of FE modelling approach used is further evaluated by comparing the thermal and deflection predictions with the test data obtained from WFRC 67756 slim floor test. Like in the previous case, comparisons for thermal predictions are performed for distinct locations on steel and in concrete with the test data. It can be seen in Figure 6 (b) that temperatures have exceeded $1000^{\circ} \mathrm{C}$ after a standard fire exposure of 120 minutes on the exposed parts of steel and concrete. As expected, temperatures are higher on the exposed lower parts and reduce with increasing distance towards the unexposed faces from the fire source. Temperature predictions for thermocouple locations on the steel section are plotted in comparison with the test data for section A-A and section B-B in Figure 11. It is seen that the predicted temperatures are in very good agreement with the test data for the steel part. Thermal predictions obtained for thermocouple locations in concrete, shown in Figure 12, are also in good agreement with the test data.

270 Deflected shape of WFRC 67756 slim floor assembly obtained at the end of FE modelling is given in 271 Figure 13. As in the case before, deflections are maximum in the middle and reduce with increase in 272 distance towards the supports. Predicted mid-span deflection, given in Figure 14, is in very good agreement with the recorded test data. Fire resistance of this slim floor assembly is predicted to be 75 minutes. At this point, the rate of deflection increased rapidly resulting in loss of stiffness and strength, hence, failure occurred. Deflection data recorded during the test shows that failure occurred at 76 minutes due to high deflection rate. Hence, the results predicted through FE modelling are in very good agreement with the test data. It is seen that the deflection trend and the mode of failure is also similar. 
For both beams, minor differences in the results on structural response can be attributed to the differences in strength of materials in case of tests and FE modelling. During FE modelling, yield strength of the structural steel is used as a representation of its strength while in the case of tests, its ultimate strength contributes to its capacity.

\subsection{The intumescent coating}

Test data on the behaviour of intumescent coating material in fire is provided in terms of temperature development at a thermocouple location on exposed leg of steel angle on which it is applied. It is seen in Figure 15 that there is a substantial temperature difference between the exposed surface of intumescent coating and the adjacent steel part on which it is applied. This difference results from the lower thermal conductivity of the intumescent coating which at elevated temperatures expands and protects steel from direct exposure to higher temperatures. During the test, temperature was recorded for a period of 180 minutes in the middle of exposed leg at thermocouple location 1 as shown in Figure 3. Thermal predictions at this location are plotted against the recorded test data and are presented in Figure 16. It is seen that FE modelling results are in very good agreement with the test data, hence, this FE modelling approach gives a good prediction of thermal behaviour of the intumescent coating applied during this test. In other words, this FE modelling procedure provides good predictions for thermal behaviour of the intumescent coating applied as a fire protection material on steel.

\subsection{Slim floor systems with intumescent coating}

FE modelling for slim floors, assumed to be protected with intumescent coating applied on the exposed lower flange, is performed by combining the verified models from sections 3.1 and 3.2, details of FE modelling have been provided earlier in section 3.3. It is seen in Figure 17 that the presence of intumescent coating on the exposed surfaces of the lower flange reduces the temperatures on the steel section significantly in comparison to those predicted for the unprotected slim floors. For the parts of the steel section which are close to the exposed surface, the reduction in temperature is more substantial and this difference reduces with the increase in distance towards the unexposed surfaces. The steel part on the far side are less influenced by the application of intumescent coating as they are already encased by concrete slab protecting them from direct exposure to fire. Further, structural response has also improved significantly.

Thermal predictions for WFRC 66162 protected assembly have been plotted against the previous thermal predictions obtained for unprotected case as shown in Figure 18. It is seen that the predicted temperatures have significantly reduced in the steel for section A-A and section B-B. In case of unprotected assembly, maximum temperatures were predicted to reach $800^{\circ} \mathrm{C}$ after 60 minutes fire exposure at thermocouple location 1. However, in case of the protected assembly, these temperatures are below $400^{\circ} \mathrm{C}$ for the same duration of standard fire exposure for the same location. For the same slim floor assembly, maximum temperatures were predicted to be more than $1000^{\circ} \mathrm{C}$ for the unprotected 
313 case for an exposure of 120 minutes which now has reduced and is just above $600^{\circ} \mathrm{C}$ for the same 314 duration of heating at same location. Reduced temperature predictions indicate that the protected slim 315 floors will undergo lesser deflections as the strength and ductility of materials will remain higher being 316 at lower temperatures displaying higher fire resistance.

317 The structural response for WFRC 66162 protected slim floor is presented in terms of the predicted 318 mid-span deflections obtained from the FE modelling. For comparison purposes, deflections for 319 protected and unprotected case are also plotted in Figure 19. In case of protected slim floor assembly, 320 deflection has reduced significantly and is $49 \mathrm{~mm}$ after 120 minutes and under a degree of utilization of 0.423 . This is much lesser than the deflection predicted for unprotected assembly for which it was $186.5 \mathrm{~mm}$ after 102 minutes of standard fire exposure under the same loading conditions. Hence, the protected slim floor assembly displayed a fire resistance of more than 120 minutes under a degree of utilization of 0.423 exposed to standard fire. It should be noted that the FE analysis was stopped after 120 minutes at which the floor assembly continued to support the applied loads.

Temperature prediction for assumed protected WFRC 67756 assembly also reduced significantly in comparison to the unprotected case. Temperature predictions are plotted for protected and unprotected cases in Figure 20. Like in the previous case, maximum temperatures remain within $400^{\circ} \mathrm{C}$ for a fire exposure of 60 minutes. For 120 minutes fire exposure, maximum temperatures have slightly exceeded $600^{\circ} \mathrm{C}$ at thermocouple location 1 . It should be noted that predicted maximum temperatures were significantly higher for same slim floor assembly without fire protection. Concrete and steel decking were not protected with intumescent coating during the FE modelling, hence, no comparisons are made for thermocouple locations in concrete or decking.

334 Mid-span deflection for protected WFRC 67756 assembly is plotted against that predicted for the 335 unprotected case and is given in Figure 21. Maximum deflection predicted is $48 \mathrm{~mm}$ for a standard fire 336 exposure of 120 minutes and under 0.390 degree of utilization, the same in case of unprotected assembly was $150 \mathrm{~mm}$ after 75 minutes. Hence the protected assembly displayed a fire resistance of more than 338120 minutes as it continued to support the applied loads. Here again, FE analysis was stopped after 120 339 minutes.

340 For protected slim floors, FE modelling for the slim floors protected with intumescent coating was further extended to predict their response in fire under their full degree of utilization, i.e., without any reductions in applied loads. There can be instances where external loads remain unchanged during a fire event and the applied fire protection is intended to enhance the fire resistance time in such load conditions. Results show that the deflections were higher for both slim floors with full degree of utilization in comparison to those with lower degree of utilization. It can be seen in Figure 22 that 
again displayed a fire resistance of more than 120 minutes at which the deflection was $222 \mathrm{~mm}$ and rate of deflection was $5 \mathrm{~mm} / \mathrm{min}$ and the floor assembly continued to support the applied loads.

349 In case of protected WFRC 67756, predicted fire resistance was 110 minutes under full degree of utilization as shown in Figure 23. At this point, rate of deflection was rapid and failure occurred due to loss of strength and stiffness of materials. For both protected slim floors, temperatures in the steel section remained below $400^{\circ} \mathrm{C}$ for a fire exposure of 60 minutes, hence, they displayed a higher fire resistance under full loading. It is seen in Figure 22 and Figure 23 that the protected slim floors offer a higher fire resistance under full loading as compared to the unprotected floors with lower degrees of utilizations of 0.423 and 0.390 respectively.

\section{CONCLUSIONS AND FUTURE WORK}

This research presents a FE modelling approach to predict the thermal and thermo-mechanical response of unprotected and protected slim floors in fire. Initially, FE modelling has been performed for unprotected slim floor tests and for a test conducted on steel angle with intumescent coating applied on its surface. Predicted results have been verified against the data acquired during the test. The verified FE models have then been combined to model the thermal and thermo-mechanical response of slim floors with protected bottom flanges. The assumed protected slim floors are similar to those used in tests except that a layer of intumescent coating is applied on the bottom flange. Fire performance of slim floors, protected and unprotected are not covered by the current Eurocodes, hence, this study can contribute to devise simple fire design methods for these types. Conclusions from this study and the potential future developments have been listed below;

- FE modelling approach used in this study predicts thermal and structural behaviour of slim floors in fire.

- Unlike traditional composite floorings where majority of steel section is exposed to fire and resulting web and top flange temperatures are high, concrete in slim floors provides encasement to the steel section, as a result, the temperature developments in these parts remain low even for higher durations of fire exposure.

- Slim floors have a very high temperature gradient across their section.

- Temperature developments and structural performance in terms of vertical deflections predicted using FE modelling are in very good agreement with the test data. Hence, this approach can be used to predict structural response of unprotected slim floors in fire.

- Results on the thermal response of intumescent coating show that the FE modelling approach used can predict this behaviour at elevated temperatures.

- Temperatures in steel section are significantly reduced due to the presence of a fire protection material which results in better fire resistance. 
- Thermal predictions for protected slim floors show that temperatures in steel section remain within $400^{\circ} \mathrm{C}$ for a 60 minute of fire exposure.

- Lesser temperatures in steel part for protected slim floor improves its fire resistance as the protected slim floors offer a fire resistance of more than 120 minutes under degrees of utilization of 0.423 and 0.390 .

- Protected slim floor assemblies offer a higher fire resistance even for loadings representing their full capacity at ambient temperatures.

As this study is limited only to FE modelling, experimental investigations on protected slim floors need to be performed to study their response in fire and to estimate the accuracy of the FE modelling approach presented in this study.

\section{REFERENCES}

1. [X. Lu and P. Mäkeläinen], [1996] '[Slim Floor Developments in Sweden and Finland]', [Structural Engineering International, Vol. 6, No. 2, pp. 127-129.]

2. [D.L.Mullet], [1998] '[Composite Floor Systems]', [The Steel Construction Institute,1st edition London.]

3. [G. M. Newman], [1995] '[Fire resistance of slim floor beams]', [Journal of Constuction Steel Research, Vol. 33, No. 1-2, pp. 87-100.]

4. [D. E. Wainman], [1996] '[Preliminary Assessment of the Data arising from a Standard Fire Resistance test Performed on a Slimflor Beam at the Warrington Fire Research Centre on 14 $4^{\text {th }}$ February, 1996]', [Technical Note, SL/HED/TN/S2440/4/96/D.]

5. [The Steel Construction Institute], [2008] '[Slimflor Compendium]', [Report to Corus, CSD, Document RT1117, Version 01.]

6. [Bilotta A., de Silva D., Nigro E.], [2016] '[Tests on intumescent paints for fire protection of existing steel structures]', [Construction and Building Materials. Vol. 121, pp. 410-422. DOI: 10.1016/j.conbuildmat.2016.05.144.]

7. [Naveed Alam, Donetella de Silva, Ali Nadjai, Emidio Nigro], [2017] '[FE Modelling for Response of Slim Floor Systems in Fire and Effects of Intumescent Coating]', [2 ${ }^{\text {nd }}$ International Fire Safety Symposium, Naples Italy, June 7-9, IFireSS , 2017]

8. [International Standards Organization], [1999] '[ISO 834-1]', [Fire Resistance Tests- Elements of Building Construction. Part 1: General Requirements.]

9. [Nigro E., Pustorino S., Cefarelli G., Princi P], [2010] '[Fire Design of steel and steel-concrete composite structures according to Eurocodes and Technical Code for Constructions]', [Hoepli, Milano.]

10. [ABAQUS], [2016] '[Finite Element Modelling Programme and Standard User's Manual]', [VVersion 6.14. SIMULIA.] 
11. [European Committee for Standardization], [2014] '[BS EN 1994-1-2: Eurocode 4: Design of composite steel and concrete structures - General rules - Structural fire design]', [European Committee for Standardization, Vol. 3.]

12. [European Committee for Standardization], [2008] '[BS EN 1992-1-2 Eurocode 2: Design of concrete structures part 1-2 General rules - Structural fire design]', [European Committee for Standardization, Vol. 3.]

13. [European Committee for Standardization], [2009] '[BS EN 1993-1-2 Eurocode 3: Design of steel structures, Part 1-2, General rules - Structural fire design]', [European Committee for Standardization]

14. [Chrysanthos Maraveas, Thomas Swailes; and Yong Wang], [2012] '[A detailed methodology for the FE analysis of asymmetric slim floor beams in Fire]', [Steel Construction, vol. 5(3), pp. 191-198, DOI: 10.1002/stco.201210024]

15. [Chrysanthos Maraveas, Thomas Swailes; and Yong Wang], [2012] '[A detailed methodology for the FE analysis of asymmetric slim floor beams in Fire]', [Nordic Steel Construction Conference, Oslo, Norway, 5-4 September.]

16. [Chrysanthos Maraveas, Konstantinos Tsavdaridis and Ali Nadjai], [2017], '[Fire Resistance of Partially Unprotected Ultra Shallow Floor Beams (USFB): A Numerical Investigation]', [ Fire Technology, vol. 53(2), pp. 609-627, DOI: 10.1007/s10694-016-0583-5]

17. [S. Bourbigot, M. Le Bras and R. Delobel], [1995] '[Fire Degradation of an Intumescent Flame Retardant Polypropylene using the Cone Calorimeter]', [Journal of Fire Sciences]

18. [Steel fire test data], [2017], '[http://www.steelconstruction.info/Steel_fire_test_data.]' 


\section{Tables}

Table 1: Geometric properties of steel section, WFRC 66162

\begin{tabular}{r|l|c|c}
\hline S \# & Description & Nominal (mm) & Actual (mm) \\
\hline 1 & Beam Depth & 280 & 279 \\
\hline 2 & Beam Width, Top Flange & 180 & 183 \\
\hline 3 & Beam Width, Bottom Flange & 280 & 280 \\
\hline 4 & Thickness Average, Top Flange & 18 & 16.6 \\
\hline 5 & Thickness Average, Bottom Flange & 18 & 18.4 \\
\hline 6 & Thickness, Web & 18 & 19.5 \\
\hline
\end{tabular}

Table 2: Geometric properties of steel section, WFRC 67756

\begin{tabular}{r|l|c|c}
\hline S \# & Description & Nominal (mm) & Actual (mm) \\
\hline 1 & Beam Depth & 304 & 305.8 \\
\hline 2 & Beam Width, Top Flange & 190 & 198 \\
\hline 3 & Beam Width, Bottom Flange & 300 & 306 \\
\hline 4 & Thickness Average, Top Flange & 20 & 21.7 \\
\hline 5 & Thickness Average, Bottom Flange & 20 & 20.6 \\
\hline 6 & Thickness, Web & 18 & 17.2 \\
\hline
\end{tabular}

Table 3: Properties of intumescent coating (17)

\begin{tabular}{l|c}
\hline Specific heat $[\mathrm{J} / \mathrm{kgK})]$ & 1200 \\
\hline Density $\left[\mathrm{kg} / \mathrm{m}^{3}\right]$ & 200 \\
\hline Water content & 0 \\
\hline Convection coefficient on exposed surfaces & 20 \\
\hline Radiation emissivity & 0.95 \\
\hline
\end{tabular}




\section{Figures}
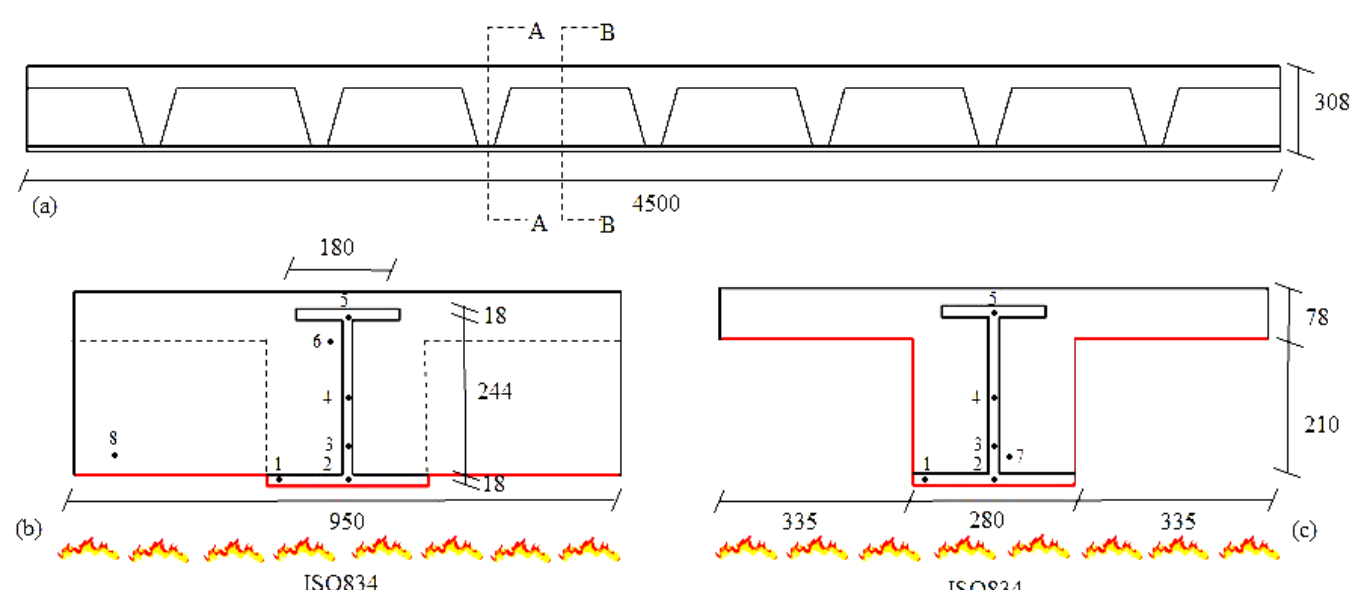

ISO834

ISO834

Figure 1: Test Assembly WFRC 66162, (a) Elevation; (b) Section at A-A; (c) Section at B-B
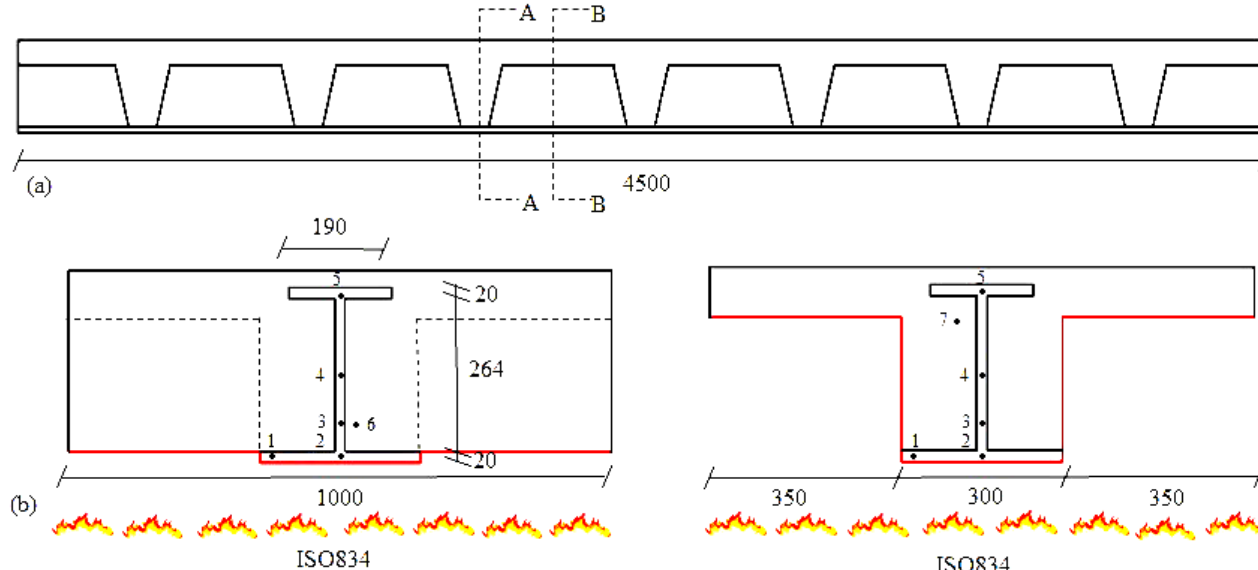

$$
500
$$

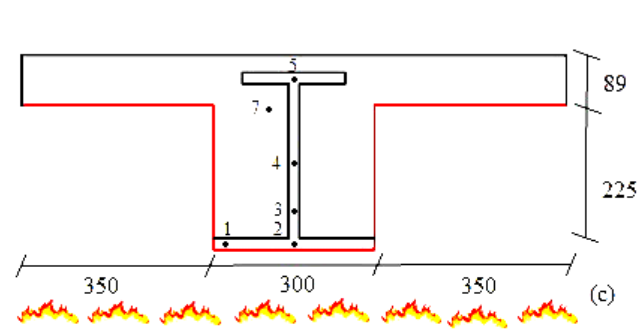

ISO 834

Figure 2: Test Assembly WFRC 67756, (a) Elevation; (b) Section at A-A; (c) Section at B-B 


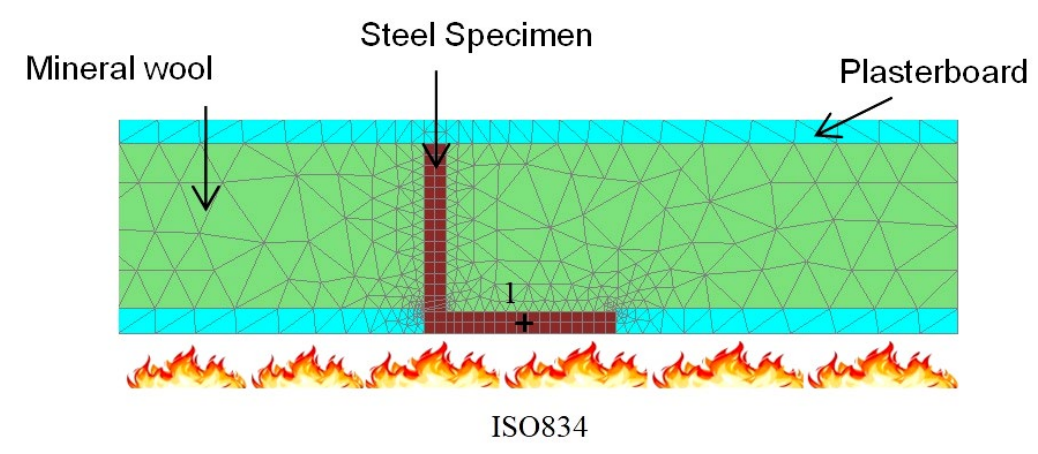

Figure 3: Test assembly for intumescent coating

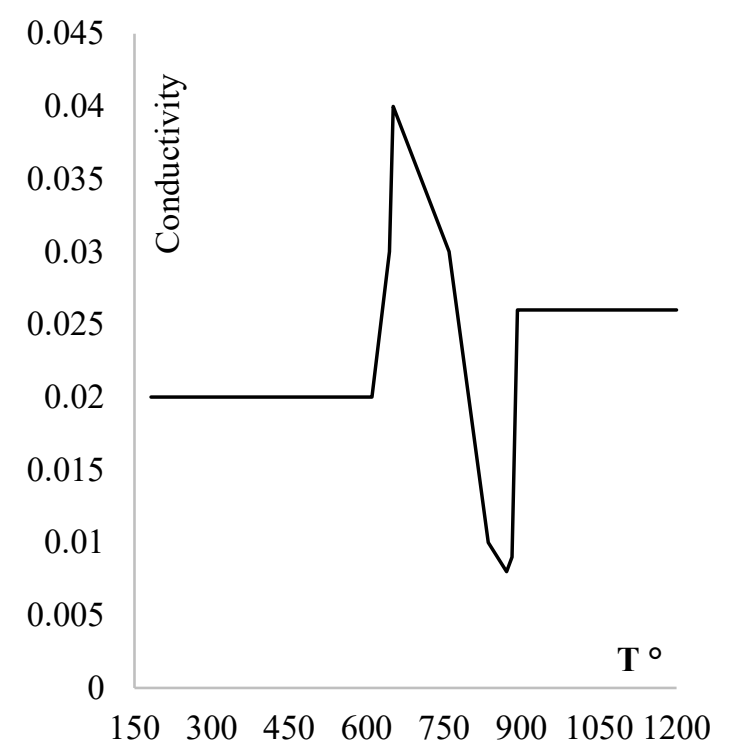

Figure 4; Thermal conductivity of intumescent coating at different temperatures (6) 


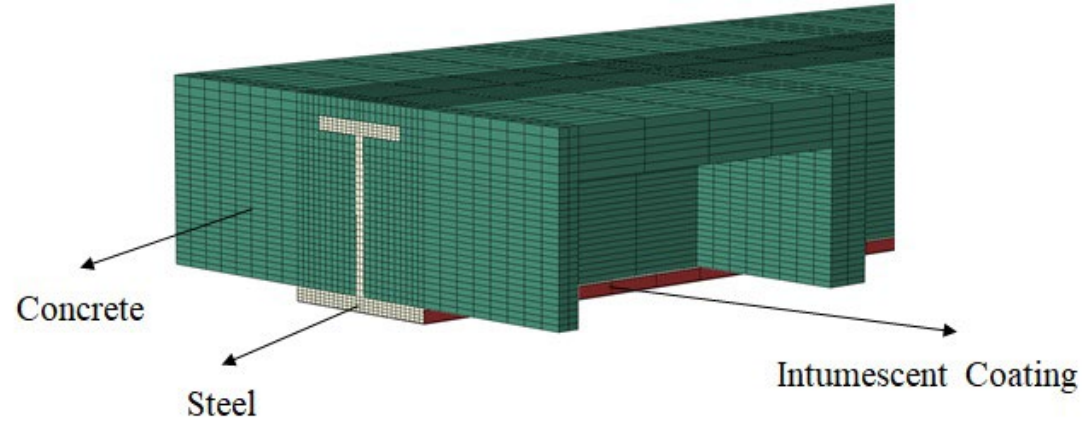

Figure 5: Slim floor protected with intumescent coating
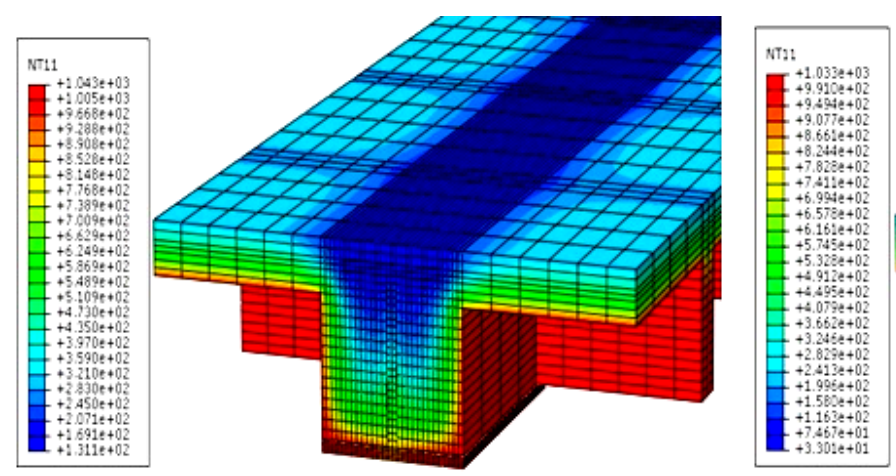

(a)

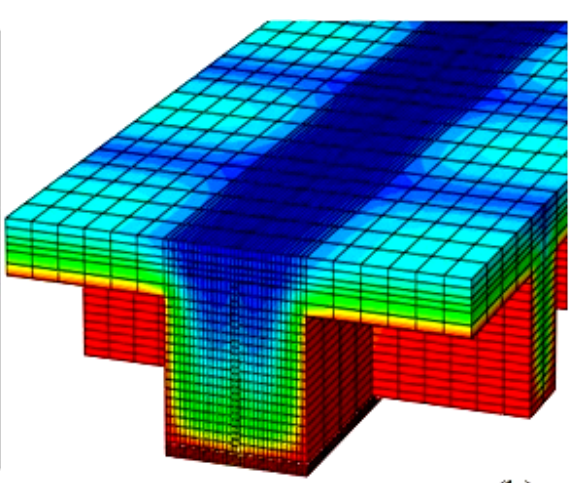

(b)

Figure 6: Thermal predictions for unprotected slim floors; (a) WFRC 66162, (b) WFRC 67756 


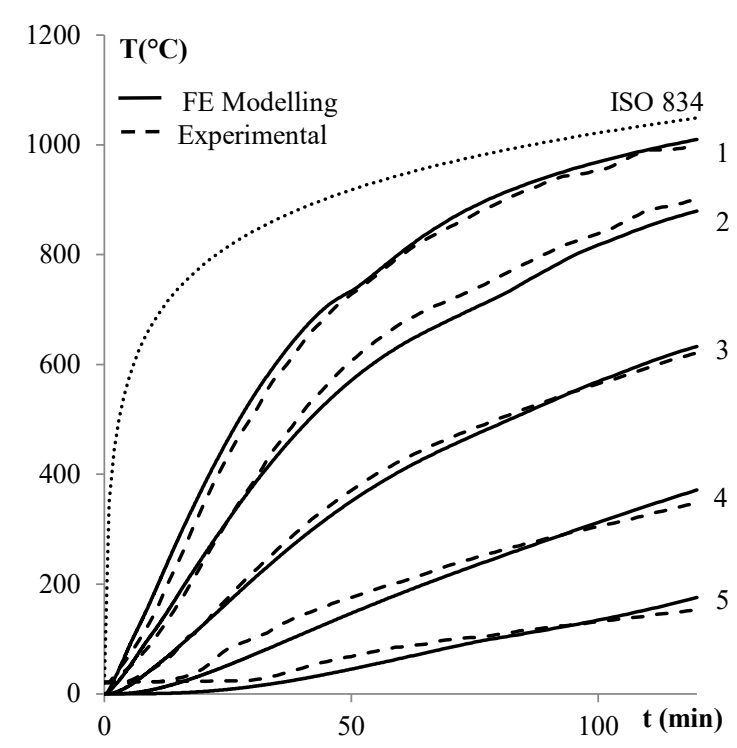

(a)

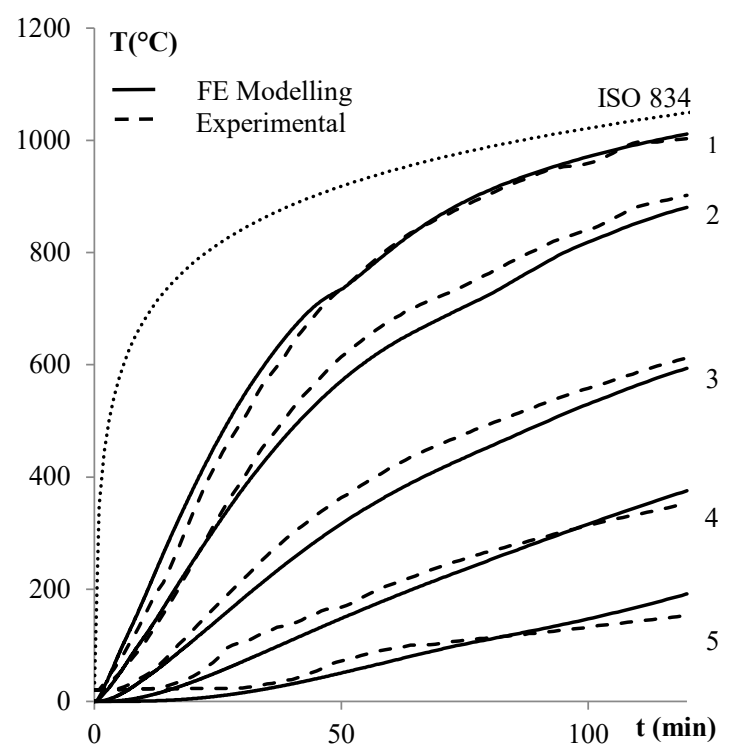

(b)

Figure 7: Thermal predictions WFRC 66162, test vs FE modelling; (a) Section A-A, (b) Section B-B

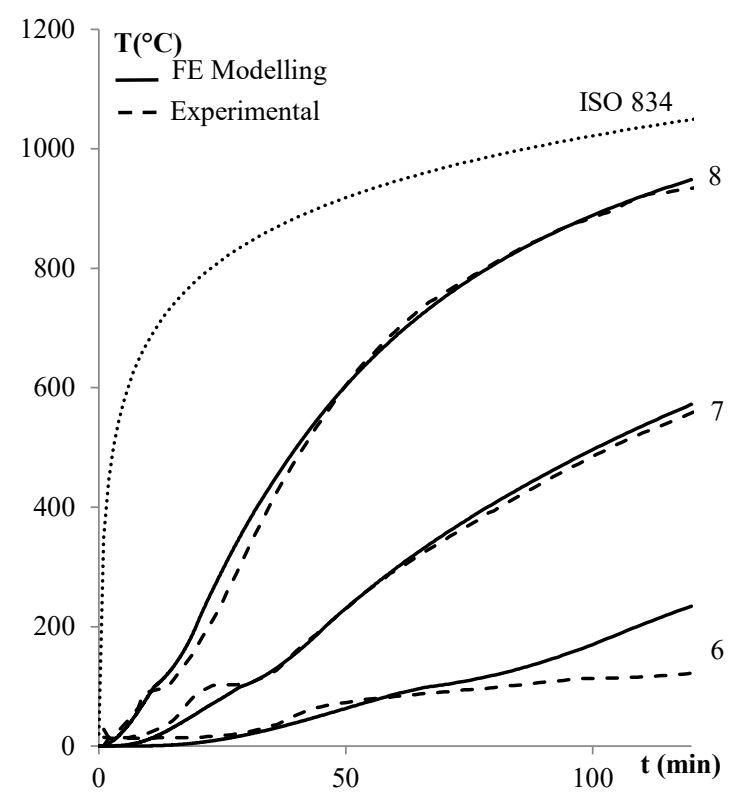

Figure 8: Thermal predictions WFRC 66162, test vs FE modelling for concrete 


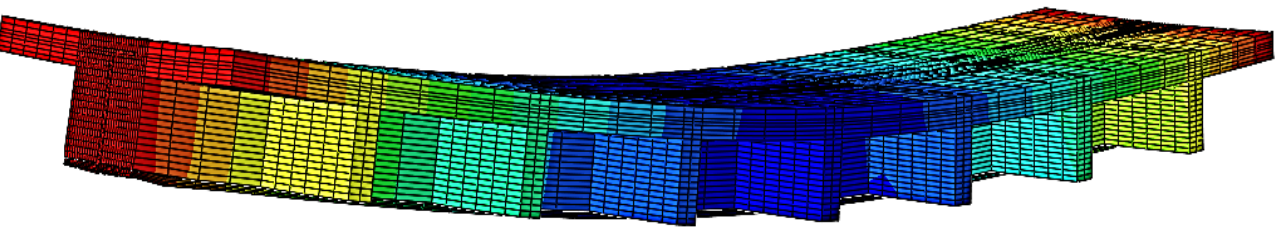

Figure 9: Deflected shape of WFRC 66162 slim floor assembly

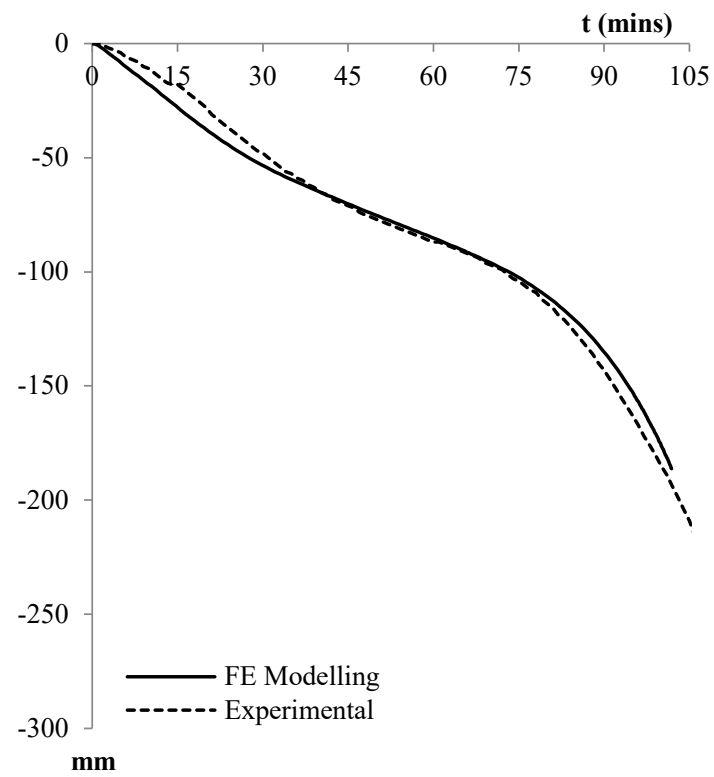

Figure 10: Test vs predicted deflection, WFRC 66162 

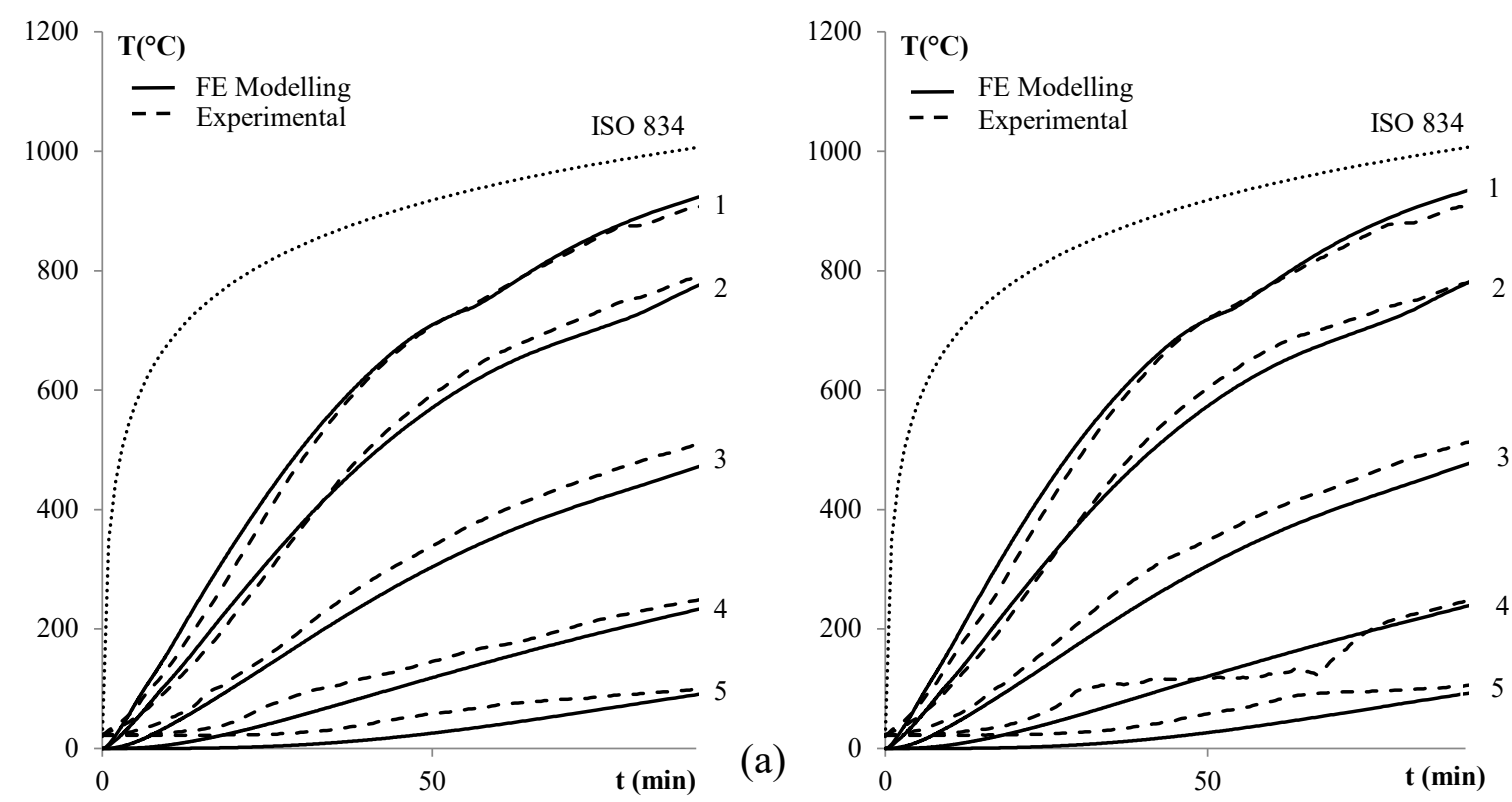

(b)

Figure 11: Thermal predictions WFRC 67756, test vs FE modelling; (a) Section A-A, (b) Section B-B

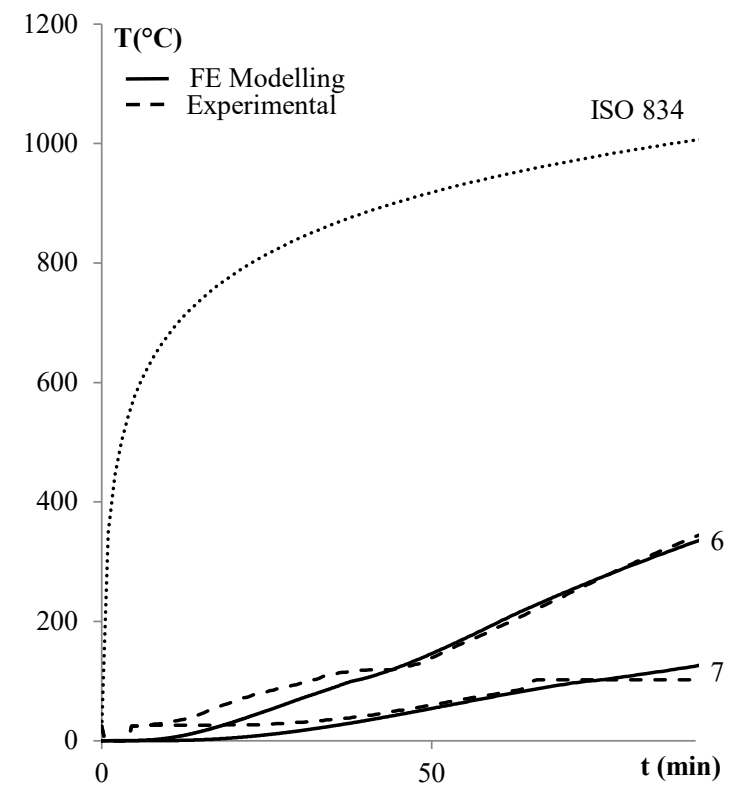

Figure 12: Thermal predictions WFRC 67756, test vs FE modelling for concrete 


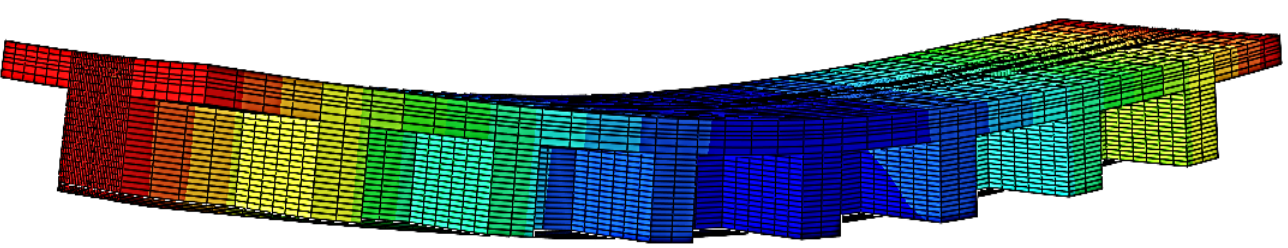

Figure 13: Deflected shape of WFRC 67756 slim floor assembly

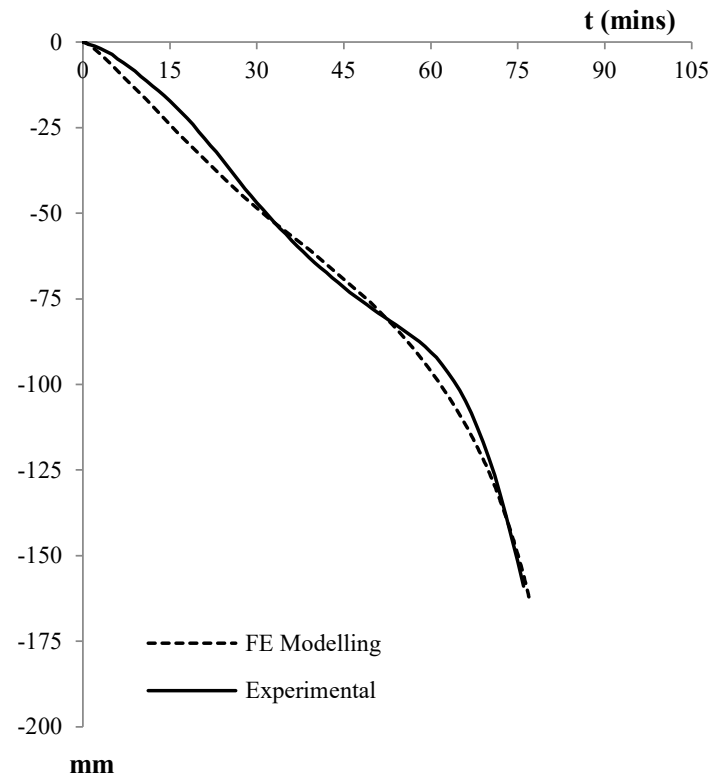

Figure 14: Test vs predicted deflections, WFRC 67756 

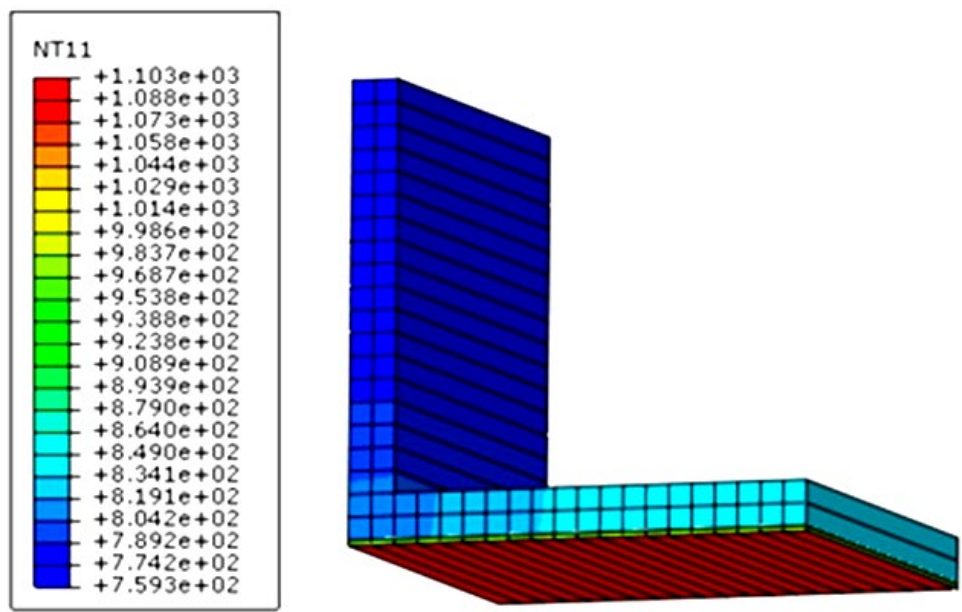

Figure 15: Thermal predictions for intumescent coating test

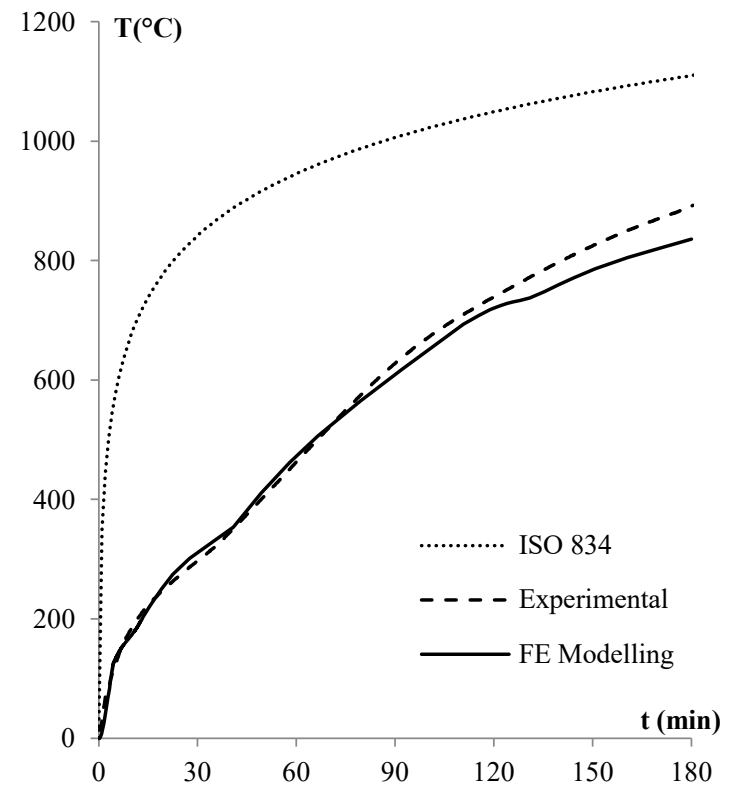

Figure 16: IC Thermal predictions test vs FE modelling for intumescent coating test 


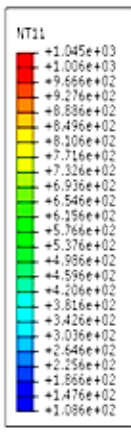

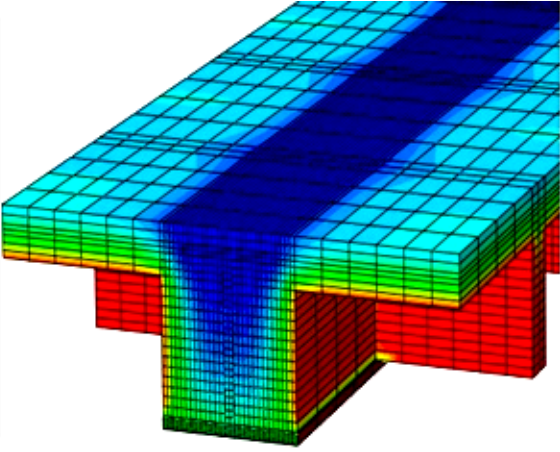

(a)

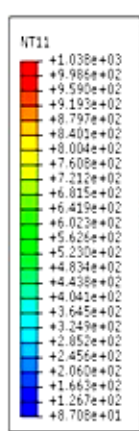

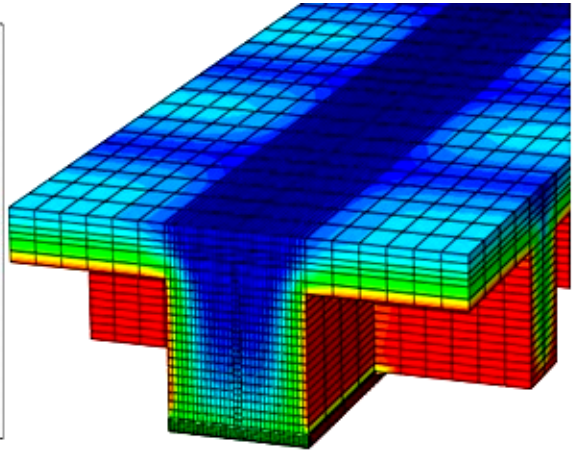

(b)

Figure 17: Thermal predictions for protected slim floors; (a) WFRC 66162, (b) WFRC 67756
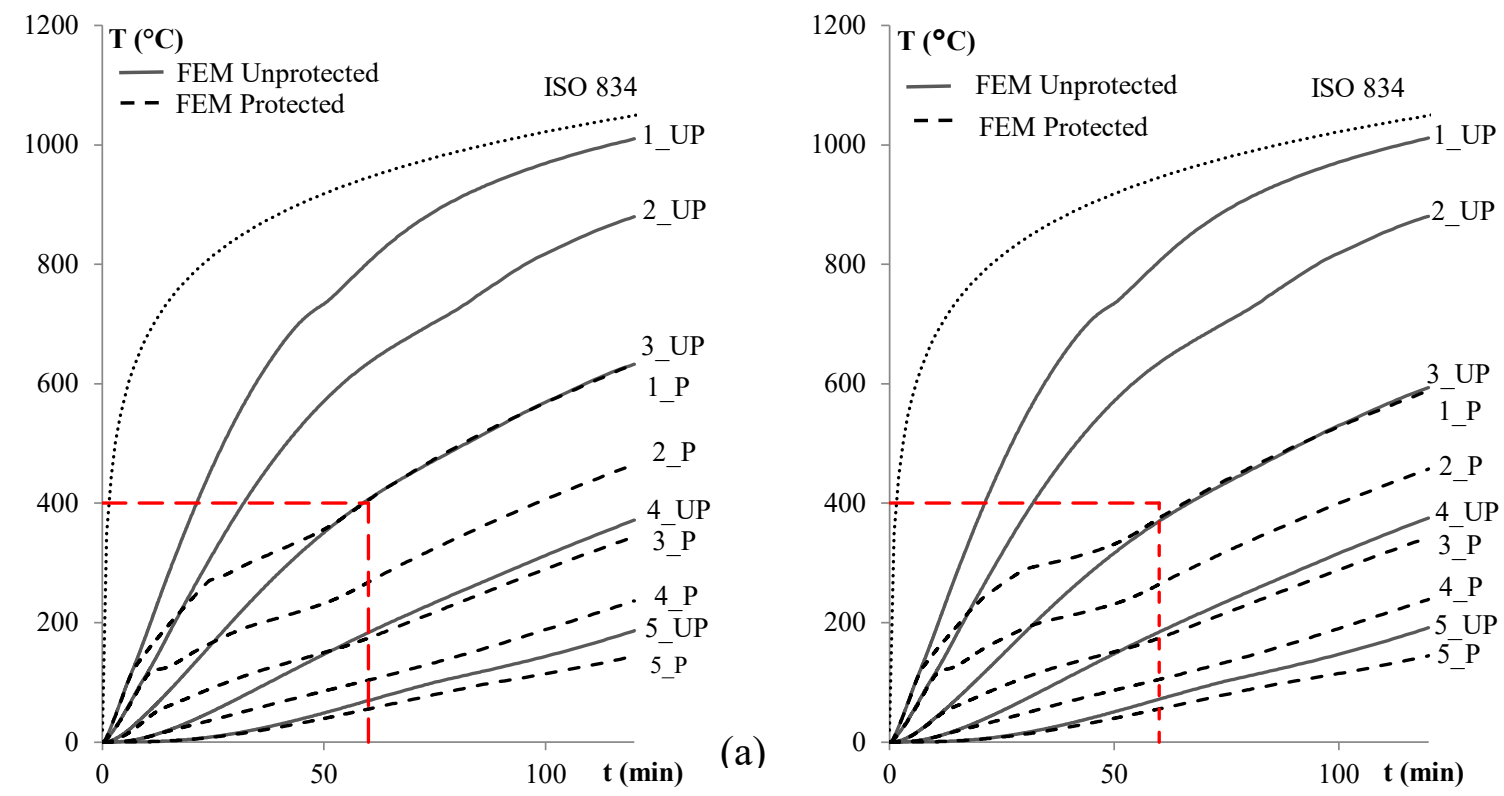

(b)

Figure 18: Unprotected (UP) vs protected (P) thermal predictions WFRC 66162; (a) section A-A, (b) section B-B 


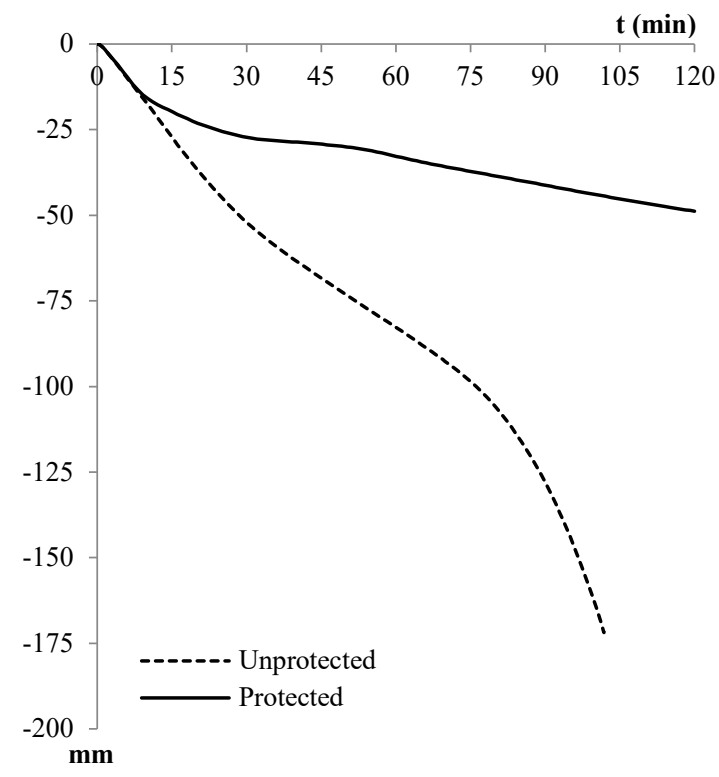

Figure 19: Protected vs unprotected, mid-span deflection, WFRC 66162
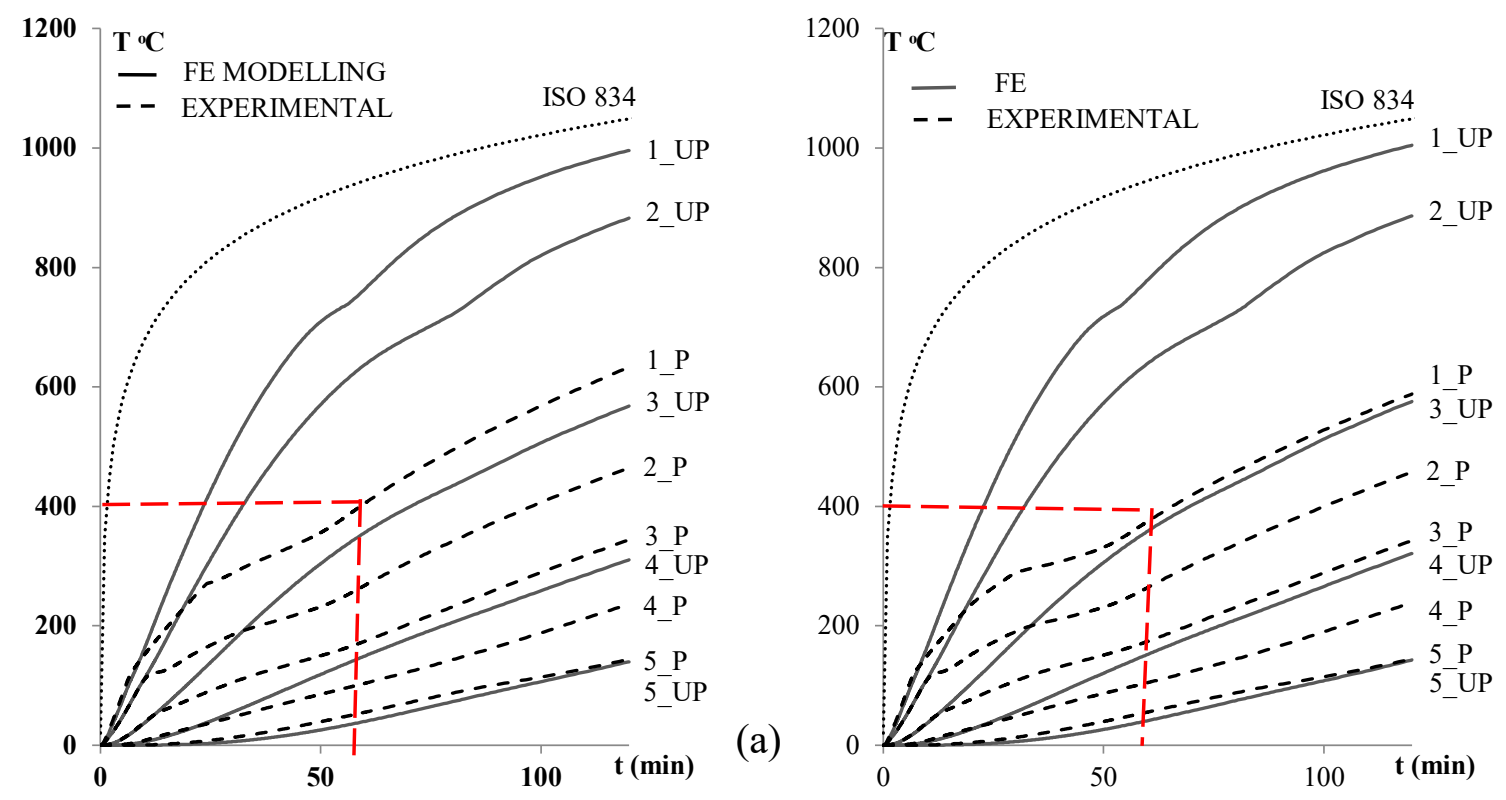

(b)

Figure 20: Unprotected (UP) vs protected (P) thermal predictions WFRC 67756; (a) section A-A, (b) section B-B 


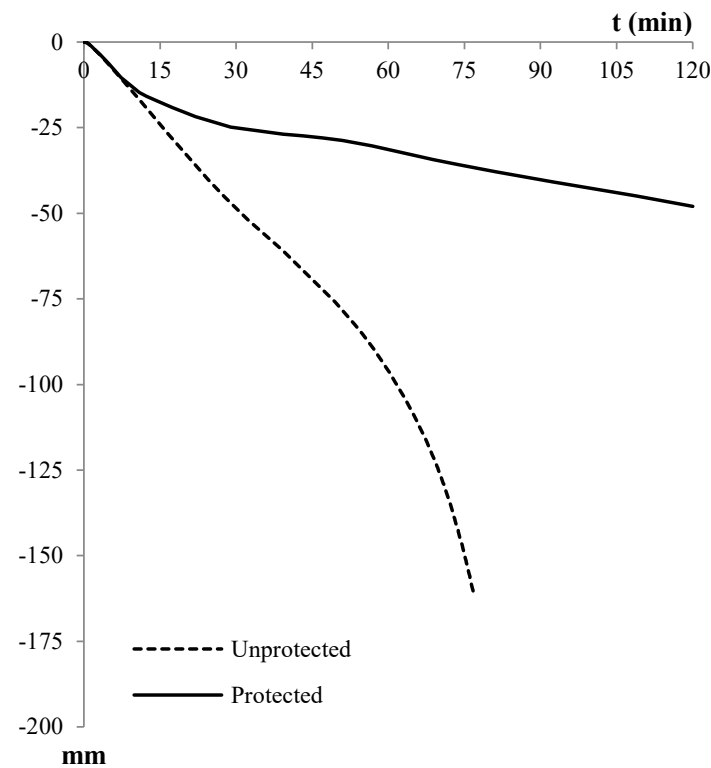

Figure 21: Protected vs unprotected, mid-span deflection WFRC 67756

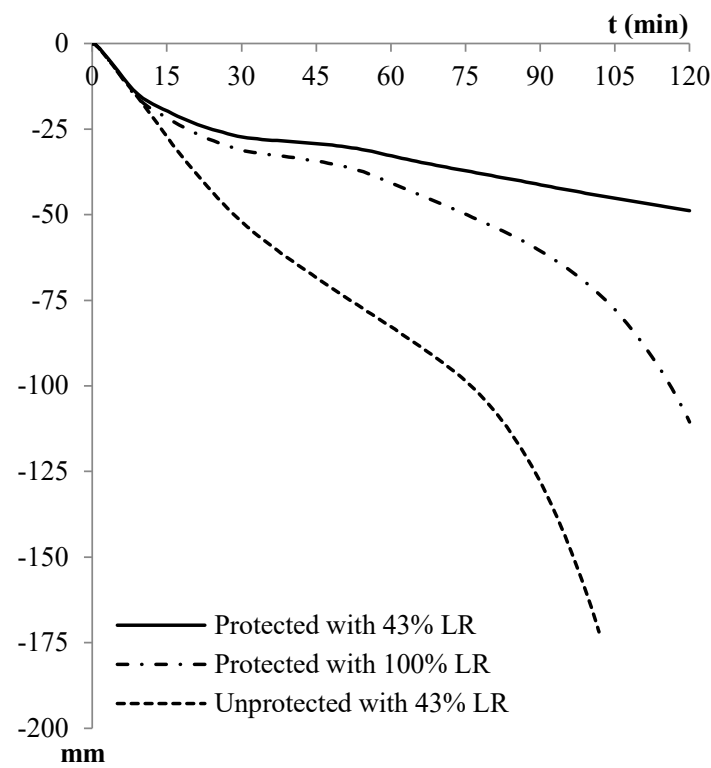

Figure 22: Mid-span deflection at different load levels, WFRC 66162 


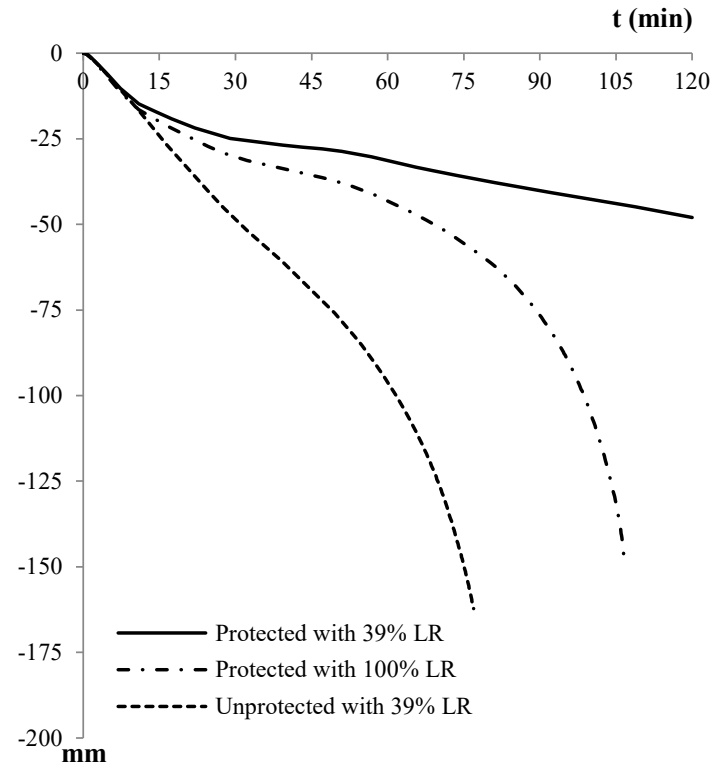

Figure 23: Mid-span deflection at different load levels, WFRC 67756 